\title{
INTELLIGENT CHEMICAL SENSOR SYSTEMS FOR IN-SPACE SAFETY APPLICATIONS
}

\author{
G. W. Hunter ${ }^{1}$, J. C. Xu ${ }^{2}$, and P. G. Neudeck ${ }^{3}$ \\ NASA Glenn Research Center \\ Cleveland, $\mathrm{OH}$ \\ D. B. Makel ${ }^{4}$ and B. Ward ${ }^{5}$ \\ Makel Engineering Inc. \\ Chico, $C A$ \\ C. C. $\mathrm{Liu}^{6}$ \\ Case Western Reserve University \\ Cleveland, $\mathrm{OH}$
}

\begin{abstract}
Future in-space and lunar operations will require significantly improved monitoring and Integrated System Health Management (ISHM) throughout the mission. In particular, the monitoring of chemical species is an important component of an overall monitoring system for space vehicles and operations. For example, in leak monitoring of propulsion systems during launch, inspace, and on lunar surfaces, detection of low concentrations of hydrogen and other fuels is important to avoid explosive conditions that could harm personnel and damage the vehicle. Dependable vehicle operation also depends on the timely and accurate measurement of these leaks. Thus, the development of a sensor array to determine the concentration of fuels such as hydrogen, hydrocarbons, or hydrazine as well as oxygen is necessary. Work has been on-going to develop an integrated smart leak detection system based on miniaturized sensors to detect hydrogen, hydrocarbons, or hydrazine, and oxygen. The approach is to implement Microelectromechanical Systems (MEMS) based sensors incorporated with signal conditioning electronics, power, data storage, and telemetry enabling intelligent systems. The final sensor system will be self-contained with a surface area comparable to a postage stamp. This paper discusses the development of this "Lick and Stick" leak detection system and it's application to In-Space Transportation and other Exploration applications.
\end{abstract}

\section{INTRODUCTION}

Future exploration missions will require significantly improved monitoring and Integrated System Health Management (ISHM) throughout the mission in the vehicle, crew habitat environments, lunar operations, and Extravehicular Activities (EVA). This implies that the inclusion of automated vehicle intelligence into the system design and operation is necessary ${ }^{1}$. Potential problems with the vehicle, robotic system, or habitat must be identified before they cause irreparable harm. In particular, in order to meet exploration mission challenges, improvement is necessary in the sensor systems, i.e., sensors and their associated data acquisition systems, packaging, communications, power, etc. In particular, the monitoring of chemical species is an important component of an overall health and operational monitoring system for space vehicles. Applications of particular interest are the monitoring of fuel leaks, fire detection, environmental monitoring, Extravehicular Activities (EVA) suit monitoring, and emissions monitoring in propulsion systems, habitats, or In-Situ Resource Utilization (ISRU) reactors.

1. Senior Electronics Engineer, Instrumentation and Controls Division, 21000 Brookpark Road, Cleveland Ohio, M-S 77-1

2. Electronics Engineer, Instrumentation and Controls Division, 21000 Brookpark Road, Cleveland Ohio, M-S 77-1

3. Senior Electronics Engineer, Instrumentation and Controls Division, 21000 Brookpark Road, Cleveland Ohio, M-S 77-1

4. President, Makel Engineering, Inc., 1585 Marauder Street,Chico, CA 95973

5. Senior Engineer, Makel Engineering, Inc. , 15505 Neo Pkwy Cleveland, OH 44128-3149

6. Professor of Chemical Engineering and Director of Electronics Design Center, Case Western Reserve University, Cleveland, Ohio 44106 
In leak monitoring of vehicle propulsion systems, detection of low concentrations of hydrogen and other fuels is important to avoid explosive conditions that could harm personnel and damage the vehicle. Dependable vehicle operation also depends on the timely and accurate measurement of these leaks. Further, since an explosive condition depends not only on the amount of fuel present but the oxygen concentration as well, the simultaneous measurement of both fuel and oxygen is an important component of a leak detection system. Thus, the development of multiple sensors (a sensor array) to determine the concentration of fuels such as hydrogen, hydrocarbon, or hydrazine as well as oxygen is necessary for in-space propulsion applications.

Work has been on-going to develop an integrated smart leak detection system based on miniaturized sensors to detect oxygen and hydrogen, hydrocarbons, or hydrazine. The approach is to implement a MEMS-based sensor incorporated with signal conditioning electronics, power, data storage, and telemetry. The final system will be selfcontained with the surface area comparable to a postage stamp. This near postage stamp sized "Lick and Stick" type gas sensor technology can enable a matrix of leak detection sensors to be placed throughout a region with minimal size and weight as well as with potentially no power consumption from the vehicle.

This paper gives an overview of the intelligent chemical sensing technology for use in In-Space Exploration applications centering on the development of chemical sensors. The examples discussed are development of hydrogen, hydrocarbons, hydrazine, and oxygen sensors. The detection method, state of maturity, and application range of each sensor is briefly discussed. The integration of these sensors into a "Lick and Stick" sensor system is also shown. The sensor system is an example of intelligent or smart sensor technology which can lead to cognitively aware vehicle systems. A discussion of possible applications of this technology to in-space propulsion and lunar exploration is given. It is concluded that a range of sensor technologies is needed for exploration applications. However, a necessary feature of these future systems is that they be modular and self-contained with increasingly smaller size, weight and power consumption with integrated intelligence.

\section{SENSOR DEVELOPMENT}

The overall approach taken in this sensor development is to apply the techniques of silicon electronics processing to produce a range of platform technologies. Three platforms are used: Schottky diodes, electrochemical cells, and resistors. ${ }^{2}$ These sensor platforms each have their own detection mechanisms and range of applications. The materials used to construct these basic platform structures are chosen by the needs of the application. By tailoring the materials for the application, a range of sensing capabilities can be achieved. ${ }^{3}$

\section{A. Hydrogen Sensor Technology}

In response to the hydrogen leak problems, NASA has endeavored to improve propellant leak detection capabilities. In particular, efforts to develop an automated hydrogen leak detection system using micro hydrogen sensors have been on-going. The objective is to produce a hydrogen leak detection system which does not need oxygen or depend upon moisture to operate. ${ }^{4-5}$ For standard leak detection operation, two different hydrogen detection approaches are used depending on the concentration range. The detection of low concentrations of hydrogen involves using palladium (Pd) alloy Schottky diodes on a silicon substrate. This type of sensor is based on metaloxide-semiconductor (MOS) technology such as that used in the semiconductor electronics industry. The gas sensing MOS structures are composed of a hydrogen-sensitive metal deposited on an oxide adherent to a semiconductor. This forms a Schottky diode in the case of a very thin layer of oxide (approximately $50 \AA$ ). The advantage of a Schottky diode sensing structure in gas sensing applications is its high sensitivity. Further, this type of sensor does not need oxygen for operation. If required, the detection of higher concentrations of hydrogen (up to 100\%) is accomplished using a resistor whose resistance is dependent on the $\mathrm{H}_{2}$ concentration.

The design of the Pd alloy sensor is shown in Figure 1. The structure includes a Pd alloy Schottky diode and resistor, a temperature detector, and a heater all incorporated in the same chip. Also shown is a picture of the packaged sensor. The response of the Schottky diodes was determined by measuring the diode's reverse current. This figure shows features present in the sensor platforms developed: small size, multiple structures on the same chip, and integration with temperature control capabilities.

The response of the Schottky diode and the resistor, both based on a palladium chrome ( $\mathrm{PdCr}$ ) alloy, is shown in Figure 2. The raw sensor data is shown as well as the processed and calibrated data. The processing includes filtering of signal noise. The response of the diode varies depending on fabrication procedure with some diodes showing more rapid responses and higher sensitivity than others. The resistor has a wide dynamic range and a response to hydrogen in air which is minimal at low concentrations but extends to $100 \%$ hydrogen. Figure $2 \mathrm{a}$ shows the response of one of the more highly sensitive diodes to hydrogen in air at low concentrations. The resistor re- 
sponse in air is shown in Figure $2 b$ to a range of high hydrogen concentrations. The calibrated response is what would be provided to the user; the processing eliminates noise in the signal and produces a more "square wave" response while still representing the concentration present in the environment.

a)

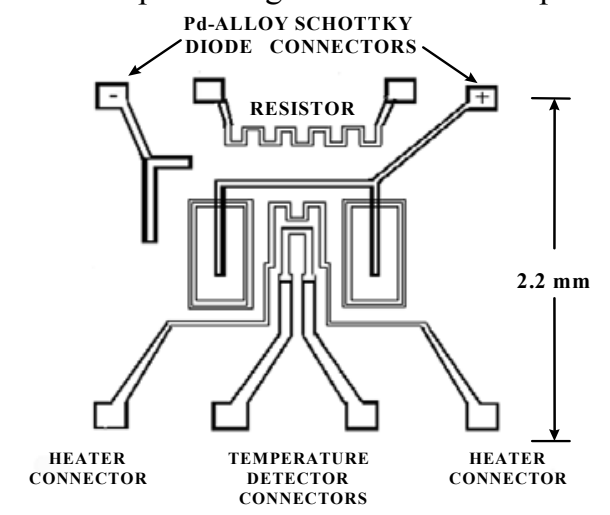

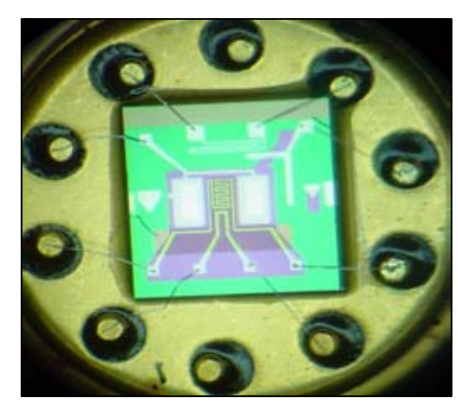

b)

Figure 1. a) Schematic diagram of the silicon-based hydrogen sensor. The Pd alloy Schottky diode (rectangular regions) resides symmetrically on either side of a heater and temperature detector. The Pd alloy resistor is included for high concentration measurements. b) Picture of the packaged sensor.

Other data taken in inert environments (not shown), i.e., helium or nitrogen, shows a diode with a slower recovery time but a more sensitive and responsive resistor. The overall approach is to combine the characteristics of both the Schottky diode and resistor to provide a reliable response throughout the range of possible operational environments of the sensor system. The resulting hydrogen sensor system that has been developed for launch vehicle applications has a wide sensitivity range and can be combined with an oxygen sensor to allow detection of explosive conditions. This hydrogen sensor has been demonstrated on the Space Shuttle, Hyper X (X-43), and the Ford Model U car, and has been qualified for use in a Criticality 1 function on the International Space Station. ${ }^{6}$ In each case, the sensor and supporting hardware were tailored for the application.

a)

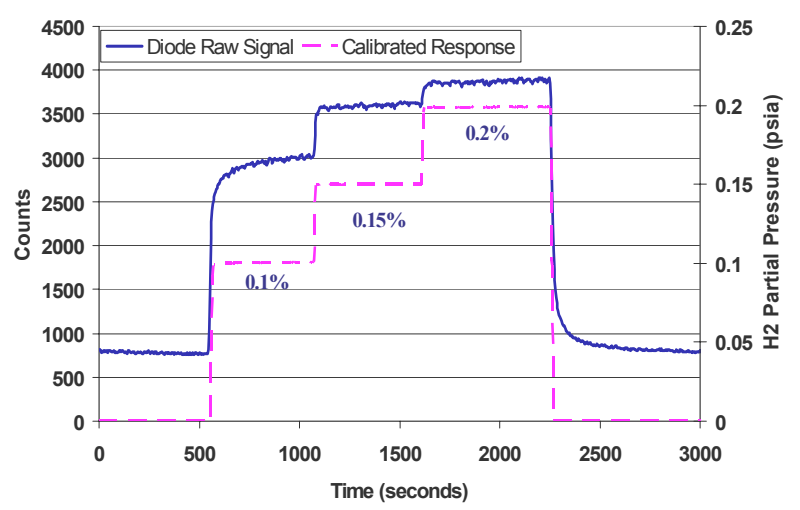

b)

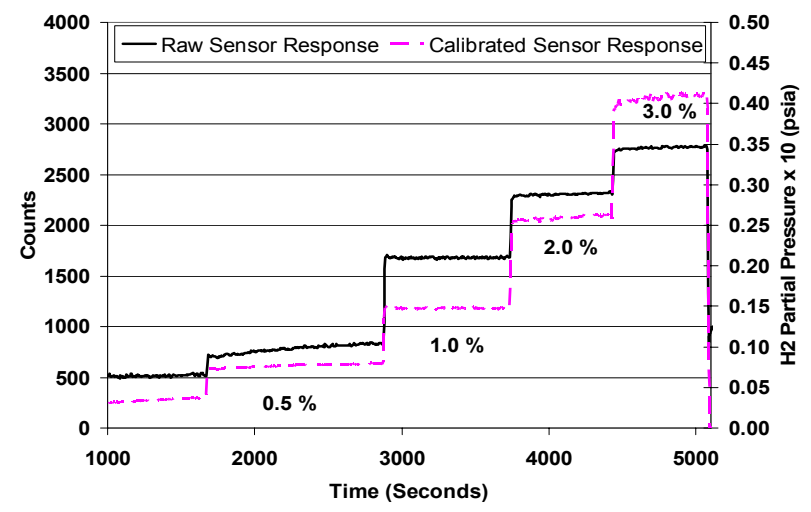

Figure 2. Pd Alloy based a) Schottky diode and b) Resistor response to hydrogen. Both the raw signal and calibrated response are shown. The responses of the two sensor types are complementary.

\section{B. Hydrazine Sensor Technology}

Hydrazine is used in a variety of fuel systems and has potential application in lunar systems. The detection of hydrazine at low concentrations is also important for International Space Station Environmental Monitoring and EVA applications. This is due to hydrazine's high toxicity; low concentrations of hydrazine (down to $10 \mathrm{ppb}$ ) can cause serious health problems for astronauts who, for example, can be exposed to hydrazine while on EVA, potentially carry the contamination on the suit, and subsequently contaminate the environment of a habitat such as the International Space Station. These applications require a hydrazine sensor to provide a real-time response in vacuum, during pressurization, and in the presence of interfering gases. 
Development of a hydrazine sensor has focused on very low concentration detection based on the design of the silicon based hydrogen sensor. While $\mathrm{PdCr}$ is used for the hydrogen application, palladium silver (PdAg) has been used in hydrazine detection utilizing an alloy combination designed for very high sensitivity. However, hydrazine is a corrosive gas and can react with a range of standard sensor packaging materials. In an effort to assure that the measured sensor response is due directly to the concentration of hydrazine and not byproducts of hydrazine/packaging reactions, a significant amount of effort has been spent on modifying the packaging surrounding the hydrazine sensor. Figure 3 shows a typical sensor package used for testing in a flow system: the objective of this packaging approach is to allow sensor exposure to the environment while at the same time minimizing exposure of metallic surfaces to hydrazine. The mounting package was also coated to minimize exposure of metallic surfaces to hydrazine. The testing took place in a vacuum chamber with hydrazine introduced to the chamber at low concentrations.

Figure 4 shows the response of a PdAg based sensor at a range of hydrazine concentrations. The magnitude and response time is proportional to the hydrazine concentration with longer response times at lower concentrations; it is unclear at the $11 \mathrm{ppb}$ level how much of the response time is due to sensor capabilities and how much is due to other factors such as diffusion of gas at these low concentrations. The lines drawn in Figure 4 illustrate that the slopes of the curves for each hydrazine concentration are noticeably different; this property can used to determine hydrazine concentration before the signal reaches equilibrium. Further work is necessary to assure repeatability of the sensor response after multiple hydrazine exposures and after exposure to interfering gases such as ammonia.

Overall, the sensor shows the capability of detecting a wide range of hydrazine concentrations down to $11 \mathrm{ppb}$. This demonstrates the capability of this sensing approach to perform very highly sensitive measurements. The range of detection also suggests the possibil-

Figure 3. The packaged hydrazine sensor for use in flow chamber conditions. The approach is to minimize the amount of packaging surface directly exposed to hydrazine.
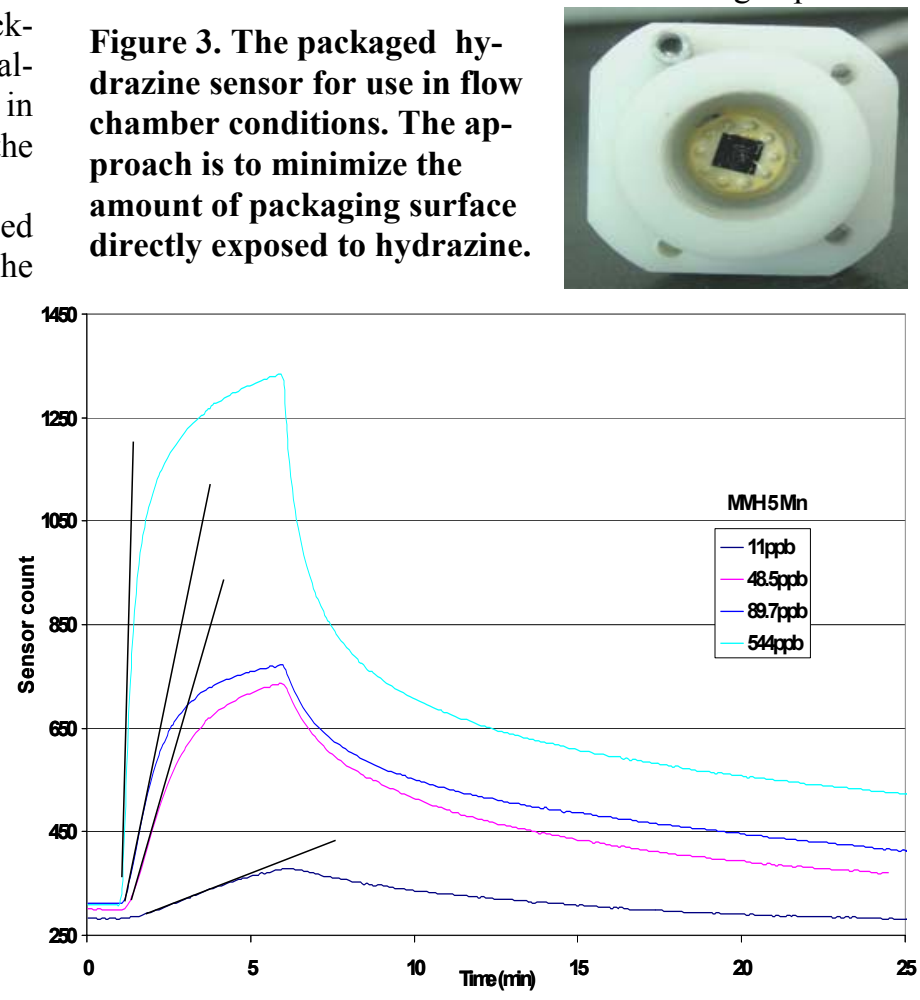

Figure 4. Response of the PdAg hydrazine sensor to a range of hydrazine (MMH) concentrations. The sensors has the capability of responding to concentrations as low as $11 \mathrm{ppb}$. ity of using this general approach for hydrazine fuel leak applications. As with hydrogen, detection of higher concentrations of hydrazine fuel leaks is important to avoid possible explosive conditions. Thus, a combination approach of a very highly sensitive with a less sensitive (wider detection range) hydrazine sensor is envisioned to allow detection for both human health safety issues and explosive fuel safety issues.

\section{Hydrocarbon Detection}

The development of hydrocarbon sensors has centered on the development of a stable silicon carbide ( $\mathrm{SiC}$ ) based Schottky diode. The advantage of $\mathrm{SiC}$ over $\mathrm{Si}$ is its ability to operate as a semiconductor at temperatures as high as $600^{\circ} \mathrm{C}$, well beyond the high temperature limits of conventional silicon semiconductor electronics. This allows SiC-based gas sensors to operate at temperatures high enough to allow the detection of hydrocarbons. ${ }^{7}$ Various structures have been investigated for high temperature stability and sensitivity. They often include barrier layers between the catalytic metal and the $\mathrm{SiC}$ semiconductor, e.g. chrome carbide $\left(\mathrm{Cr}_{3} \mathrm{C}_{2}\right) .{ }^{8}$ A variety of sensing devices have been tested and detection of multiple hydrocarbon species has been demonstrated. ${ }^{3,7-9}$

However, a major issue associated with $\mathrm{SiC}$ based hydrocarbon detection is the starting $\mathrm{SiC}$ semiconductor material. $\mathrm{SiC}$ semiconductors are still in an early development stage compared to silicon, and crystal defects in $\mathrm{SiC}$ device wafers can significantly affect device performance. While significant progress has been made using standard 
commercially available material, it is envisioned that significant performance gains would be enabled by improved $\mathrm{SiC}$ material free of crystal defects.

Figure 5 shows two side-by-side prototype $\mathrm{Pt} / \mathrm{SiC}$ Schottky sensor diodes residing on individual mesas prepared on the same $\mathrm{SiC}$ chip. One mesa (right) is specially prepared to be step-free or atomically flat $(\mathrm{AF})^{8}$ while the other (left) is not atomically flat (NAF) due to a screw dislocation defect in the $\mathrm{SiC}$ wafer. The two sensors were tested side by side on the same chip, with results shown in Figure 6.

The sensor is tested by first being exposed to air for 5 minutes, $\mathrm{N}_{2}$ for 5 minutes, $0.5 \%$ propylene in $\mathrm{N}_{2}$ for 10 minutes, pure $\mathrm{N}_{2}$ for 5 minutes, and finally air again. The sensors were tested at $100^{\circ} \mathrm{C}$ for 44 hours, $200^{\circ} \mathrm{C}$ for 145 hours, and then at $300^{\circ} \mathrm{C}$ for nearly 500 hours. The sensors had nearly the same response at $100^{\circ} \mathrm{C}$ and $200^{\circ} \mathrm{C}$. The test was stopped at near 690 hours for sample analysis. Figure 6 shows a comparison of the sensor gain in hydrogen between the AF and NAF samples at various temperatures from room temperature to $300^{\circ} \mathrm{C}$. The difference in response between these two sensors takes effect when the sensor is heated to $300^{\circ} \mathrm{C}$. The $\mathrm{AF}$ sensor gain increases dramatically compared to the NAF sensor and stabilizes near 325 hours into the testing or after nearly 200 hours at $300^{\circ} \mathrm{C}$. The gain of the AF sensor response averages nearly 145 times greater than that of the NAF sensor. Thus, the difference between the two sensors side-by-side on the same sensor chip is significant and highlights the advantages of using AF SiC surfaces.

Figure 5. The two prototype $\mathrm{Pt} / \mathrm{SiC}$ diode sensor samples tested in this paper: The left hand side is the nonatomically flat (NAF) sensor and the right hand side is the atomically flat (AF) sample. Surface morphology differences between the two sensors are noticeable in the differential interference contrast micrograph.

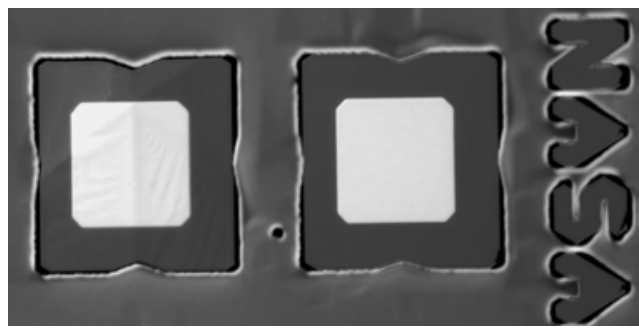

Figure 6. Comparison of sensor gain to $0.5 \%$ hydrogen between $\mathrm{Pt} / \mathrm{SiC}$ sensors deposited on atomically flat (AF) $\mathrm{SiC}(\diamond)$ and non-atomically flat (NAF) SiC (ש). At near 150 hours of testing at $200^{\circ} \mathrm{C}$, both sensors are heated to $300^{\circ} \mathrm{C}$. The difference in response gain between the sensors becomes readily evident with time at $300{ }^{\circ} \mathrm{C}$.

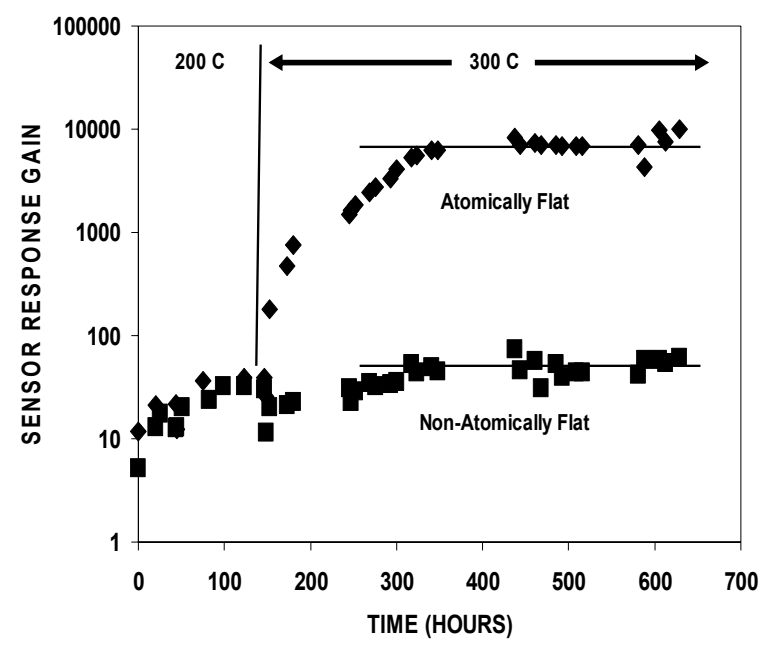

Present activities related to $\mathrm{SiC}$ based gas detection have centered on using atomically flat $\mathrm{SiC}$ as a beneficial gas sensing structure and incorporating elements such as a temperature detector and heater to allow operation in application environments. These activities are aimed at not only allowing improved hydrocarbon detection, but also hydrazine detection, given SiC's inertness and potential to be resistant to possible hydrazine corrosion at higher hydrazine concentrations. In the parallel, use of commercially available $\mathrm{SiC}$ with barrier layers such as $\mathrm{Cr}_{3} \mathrm{C}_{2}$ will continue to allow measurements at higher temperatures for nearer term applications.

\section{Oxygen Sensor}

A microfabricated $\mathrm{O}_{2}$ sensor is being developed based on electrochemical cell technology. Commercially available $\mathrm{O}_{2}$ sensors are typically electrochemical cells using zirconium dioxide $\left(\mathrm{ZrO}_{2}\right)$ as a solid electrolyte and $\mathrm{Pt}$ as the anode and cathode. The anode is exposed to a reference gas (usually air) while the cathode is exposed to the gas to be detected. Zirconium dioxide becomes an ionic conductor of $\mathrm{O}^{2-}$ at higher temperatures, e.g. $600^{\circ} \mathrm{C}$. This property of $\mathrm{ZrO}_{2}$ to ionically conduct $\mathrm{O}^{2-}$ means that the electrochemical potential of the cell can be used to measure 
the ambient oxygen concentration at high temperatures. However, operation of these commercially available sensors in this potentiometric mode limits the range of oxygen detection. Further, the current manufacturing procedure of this sensor is relatively labor intensive, costly, and results in a complete sensor package with a power consumption on the order of several watts.
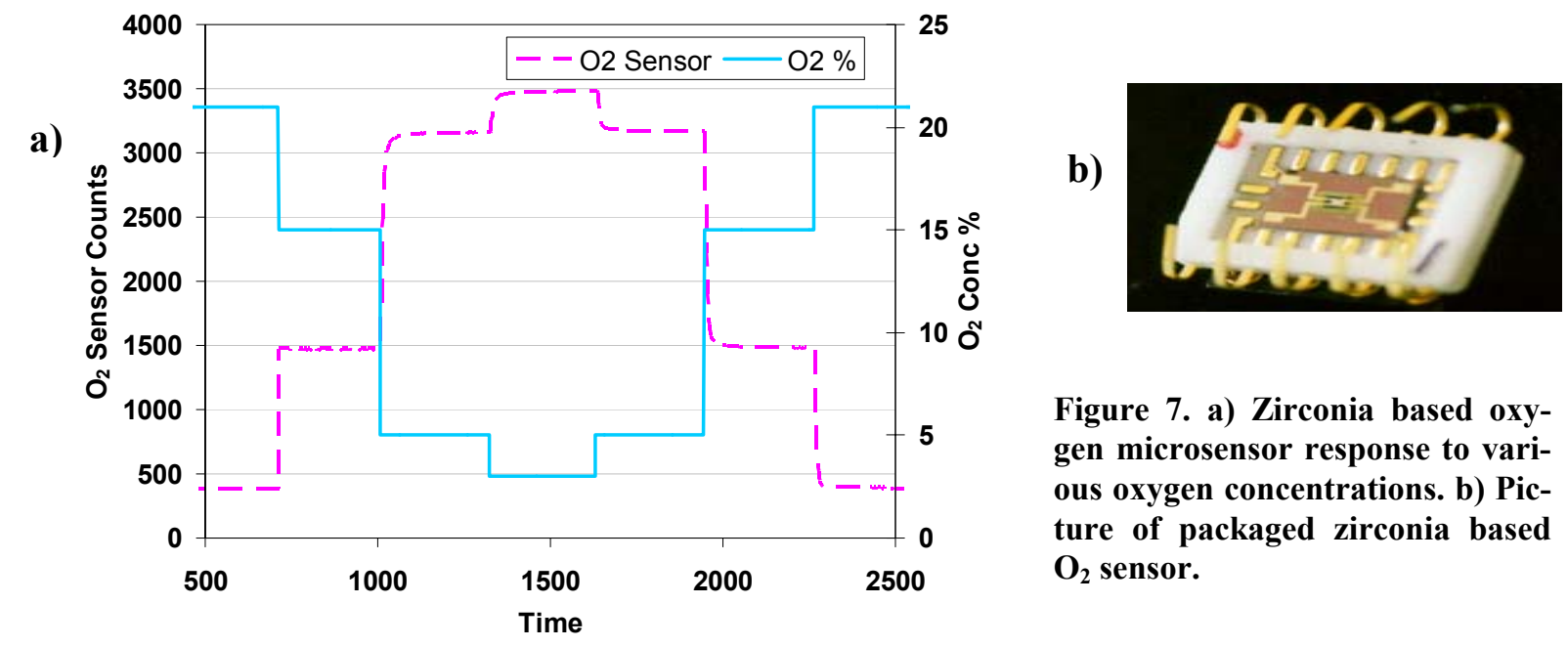

Figure 7. a) Zirconia based oxygen microsensor response to various oxygen concentrations. b) Picture of packaged zirconia based $\mathrm{O}_{2}$ sensor.

The amperometric zirconia cell oxygen sensor has been tested in multiple applications and has a nearly linear response to various concentrations of oxygen. As shown in Figure 7, an increase in oxygen concentration causes a decrease in the $\mathrm{O}_{2}$ sensor count output. The response is stable and responsive to changes in ambient $\mathrm{O}_{2}$ concentrations over a range of concentrations from $2 \% \mathrm{O}_{2}$ to $21 \%$; other data show an ability to respond to $\mathrm{O}_{2}$ concentration ranges beginning from $0 \% \mathrm{O}_{2}$. Thus, this sensor has the capability to respond to $\mathrm{O}_{2}$ over a range of concentrations.

Present activities have been underway to combine both the amperiomentric and potentiometic sensing approaches into the same sensor system. Combining these two approaches is intended to yield a wide range sensor response combined with an ability to detect at low concentrations. Other activities include the modification of this sensor design to use room temperature electrolytes to allow low power, room temperature detection of oxygen.

\section{INTEGRATED SENSOR ARRAYS}

The development of miniaturized chemical sensor microsystems for leak detection and other applications is currently underway. The approach has been to develop a "Lick and Stick" leak detection system which can be stand-alone and applied wherever and whenever necessary. The electronics design has consistently been aimed towards choosing parts which are appropriate for space applications. A range of capabilities have been built into the "Lick and Stick" system including a microcontroller, signal conditioning and temperature control, utilization of 3$5 \mathrm{~V}$ power source, wireless communications (in addition to wired RS-485), ability to operate from battery power, internal temperature and pressure measurement, and operation of up to three chemical sensors.

The present system is shown in Figure 8. The electronics board and three sensors are shown in Figure 8a while the complete electronics system and sensors is shown in Figure 8b. The "Lick and Stick" system has a surface area near that of a postage stamp and with the capabilities (and more) described above. The wireless capability can be configured for the needs of the application. Three different antennas corresponding to three different wireless systems are shown in Figure 8b; each wireless system has a different frequency range and communication distance.

Testing of a prototype model of the "Lick and Stick" sensor system is shown in Figure 9. ${ }^{8}$ The data highlights the response of the $\mathrm{SiC}$-based gas sensor at various hydrocarbon fuel (RP-1) concentrations. The oxygen concentration is held constant and the hydrogen sensor signal shows no response, suggesting a lack of cross-sensitivity between the hydrogen and hydrocarbon sensors to the detection of this hydrocarbon. The hydrocarbon sensor, a $\mathrm{Pt} / \mathrm{Cr}_{3} \mathrm{C}_{2} / \mathrm{SiC}$ Schottky diode, is able to detect fuel concentrations from $300 \mathrm{ppm}$ to $3000 \mathrm{ppm}$. The magnitude of the response to $300 \mathrm{ppm}$ RP-1 fuel suggests the ability to detect concentrations well below $300 \mathrm{ppm}$. This example demonstrates the ability to integrate these three sensors into a complete sensor array with a full complement of supporting sensor electronics and hardware. For shorter term operation, like monitoring a leak for a limited time on a launch pad, these systems can be operated using a battery. For longer term operation, further decreasing the power 
consumption of the sensors is necessary. The "Lick and Stick" sensor system is presently being matured for inclusion in the Crew Launch Vehicle (CLV) for leak detection applications.

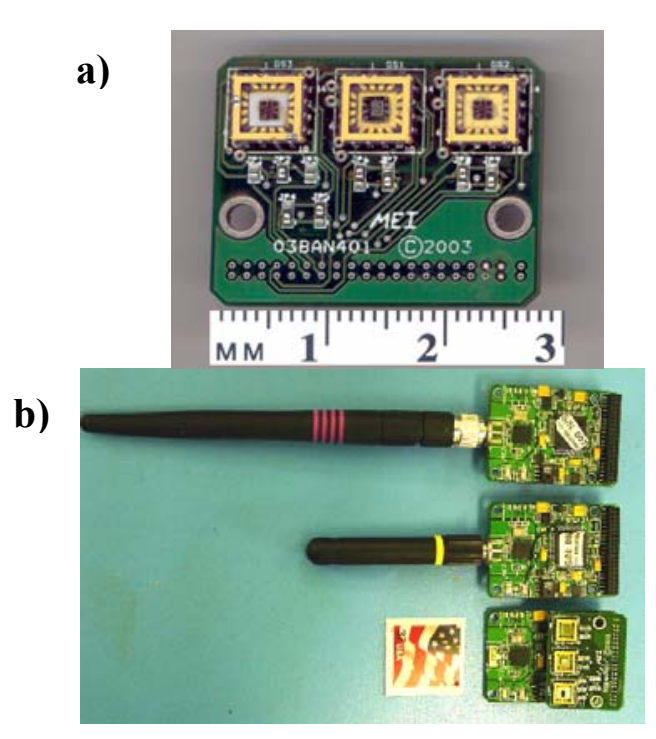

Figure 8. "Lick and Stick" Leak Detection system configured with different wireless antennae.

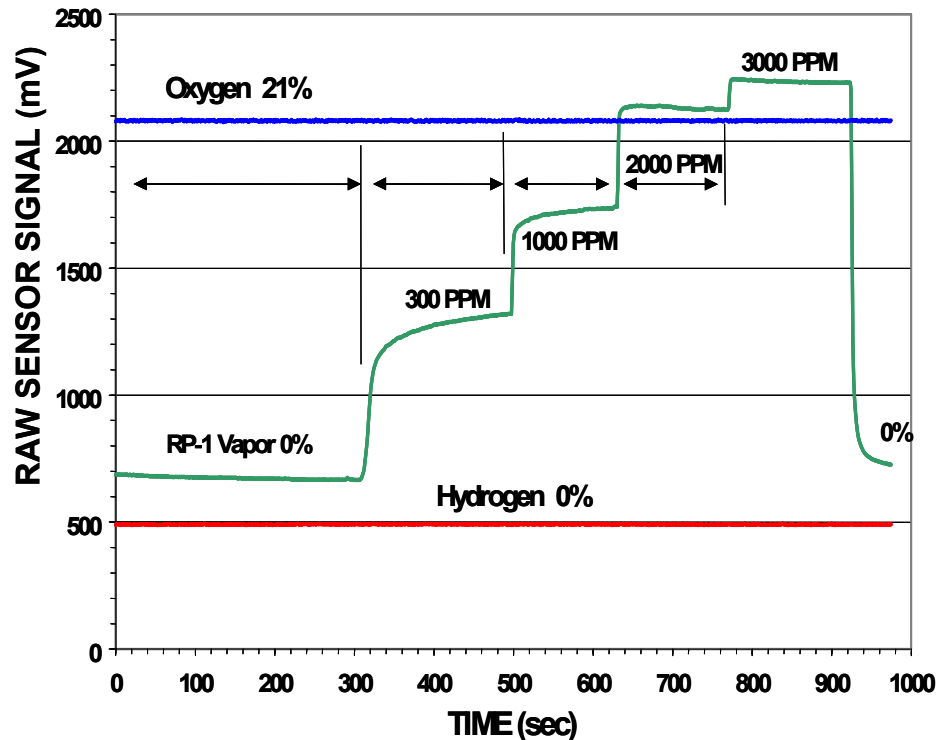

Figure 9. Response of the three sensors, (hydrogen, hydrocarbons, and oxygen) to a constant oxygen environment and varying hydrocarbon (RP-1) concentrations. The sensor signal shown is the output from the signal conditioning electronics which processes the measured sensor current at a constant voltage.

\section{EXAMPLES OF EXPLORATION APPLICATIONS}

Exploration missions will require a range of chemical sensing technologies. The base chemical sensing technology described here and elsewhere ${ }^{3}$ combined with the "Lick and Stick" electronics system can significantly contribute to these missions by providing an improved cognitive awareness of the chemical environment. This is part of an overall improvement of cognitive awareness necessary for increased automation of flight systems to enable exploration applications. A possible series of in-space/lunar applications are as follows. These are meant as brief examples of how the technology described here can impact exploration applications.

Leak detection in in-space fuel systems will require monitoring in vacuum environments to detect fuel leaks and to assure that fuels do not reach sites where it might combine with oxygen to form hazardous concentrations. The places where a leak may occur may not be anticipated before launch so the capability to place sensors where needed after launch and wirelessly feed this information to an automated system is desirable. Monitoring of toxic fuel leaks and conditions is also necessary to minimize astronaut exposure to contaminants while on EVA, whether for in-space or lunar missions. This monitoring can take place during EVA, in the airlock, and in the habitat. Lunar applications will also require safe propellant storage and operation, as well as the need to examine lunar soil for chemical composition and perform in-situ resource utilization (ISRU). One major specie of interest is water, and its constituents, hydrogen and oxygen, are some of the same species being measured in leak detection applications. These sensors might be integrated into a micro sample processing unit to provide not only sample processing but analysis as well. ${ }^{10}$

All of these applications require that the sensors be micro/nano fabricated for minimal size, weight and power consumption if they are to be easily applied in Exploration applications. Each sensor system must be tailored for the application environment. While the planned maturation of the "Lick and Stick" system for CLV will demonstrate the basic electronics and sensor structures for that application, modifications to the sensor system will be needed for in-space and lunar applications. Nonetheless, the wide range of capabilities enabled by the sensor platforms being developed can address a range of chemical species measurements and applications. The objective is to provide in- 
formation to either the automated systems or the astronauts directly to minimize workload, increase automation, and enhance capabilities to allow exploration missions to occur with limited ground support and human intervention while increasing safety and efficiency. It is suggested that without such innovations, the ability to meet exploration mission objectives would be problematic.

\section{SUMMARY}

The needs of exploration applications require the development of gas sensors with capabilities beyond those of commercial sensors. These requirements include operation in a range of environments as well as minimal size weight and power consumption. Sensor technology is being developed to address these requirements using microfabrication and micromachining technology and their integration into smart "Lick and Stick" sensor systems is ongoing. There are a range of exploration applications for such technology including in-space and lunar missions.

\section{ACKNOWLEDGMENTS}

The authors would like to acknowledge the contributions of Dr. L. Matus, J. Wrbanek, L. Oberle, L. Evans and T. Guo of NASA GRC; T. Hong of NASA Johnson Space Center, R. Young of NASA Kennedy Space Center, Dr. L. Chen, D. Spry, and A. Trunek of OAI; D. Lukco of QSS, and the technical assistance of D. Androjna, M. Artale, and P. Lampard of Sierra Lobo/NASA GRC.

\section{REFERENCES}

${ }^{1 .}$ Hunter, G. W., Oberle, L. G., Baakalini, G., Perotti, J., and Hong, T., "Intelligent Sensor Systems for Integrated System Health Management in Exploration Applications", First International Forum on Integrated System Health Engineering and Management in Aerospace, Nov. 2005, Napa, CA.

2. Liu, C.C.; Hesketh P.K.; and Hunter, G.W.; "Chemical Microsensors", The Electrochemical Society Interface, Vol. 13, No. 2. , pg. 22-29, Summer, 2004.

${ }^{3}$ Hunter, G.W.; Xu, J. C.; Liu, C. C.; and Makel, D. B.; "Microfabricated Chemical Sensors for Aerospace Applications," in The MEMS Handbook Second Edition: Design and Fabrication, Chapter 11, edited by M. Gad-ElHak, (CRC Press, 2006).

4. Hunter, Gary W.; “A Survey and Analysis of Commercially Available Hydrogen Sensors”, NASA Technical Memorandum 105878, November 1992.

${ }^{5 .}$ Hunter, Gary W.; "A Survey and Analysis of Experimental Hydrogen Sensors", NASA Technical Memorandum 106300, October 1992.

${ }^{6 .}$ Msadoques, George and Makel, Darby; "Flight Hydrogen Sensor for use in the ISS Oxygen Generation Assembly", International Conference on Evolable Systems, 05 ICES-350, Barcelona, Spain Septempber, 2005.

7. Chen, L.Y.; Hunter, G. W.; Neudeck, P. G.; Knight, D.; Liu, C. C.; and Wu, Q. H.; "SiC Based Gas Sensors", in Proceedings of the Third International Symposium on Ceramic Sensors, Anderson et. al, Editors, Electrochemical Society Inc., pp. 92-105, 1996.

8. Hunter, G. W.; Neudeck, P. G.; Xu, J.; Lukco, Trunek, A.; Artale, M.; Lampard,P.; Androjna, D.; Makel, D.; Ward, B.; and Liu, C. C. "Development of SiC-based Gas Sensors for Aerospace Applications", in Silicon Carbide 2004-Materials Processing and Devices, edited by M. Dudley, P. Gouma, T. Kimoto, P. G. Neudeck, and S. E. Saddow (Mater. Res. Soc. Symp. Proc. 815, Warrendale, PA, 2004) Materials Research Society Symposium Proceedings Series, pg. 287-298.

9. Hunter, G. W., Neudeck, P., Okojie, R., Thomas, V., Chen, L., Liu, C. C., Ward, B., and Makel, D., "Development of SiC Gas Sensor Systems" in Proceeding of the State-of-the-Art Program on Compound Semiconductors XXXVI/Wide Bandgap Semiconductors for Photonic and Electronic Devices and Sensors III, 201st Meeting of The Electrochemical Society, Philadelphia, Pennsylvania, May, 2002, pp. 287-297.

10. Carranza, S, Makel, D.B., Blizman, B., and Ward, B.J., "Microchannel Reactors for ISRU Applications," in proceedings of Space Technology and Applications International Forum (STAIF-2005), edited by M. El-Genk, AIP Conference Proceedings 746, New York, 2005, pp. 1229-1236. 